\title{
CO-EXISTENCE OF PHYSICAL ACTIVITY (PA) AND OTHER ENERGY-BALANCE RELATED BEHAVIOURS AMONG ADOLESCENTS PARTICIPATING IN PA INTERVENTION IN POLAND
}

\author{
Paweł Zembura, ${ }^{A, B}, \mathrm{C}, \mathrm{D}$ Aleksandra Gołdys ${ }^{\mathrm{A}, \mathrm{B}, \mathrm{D}}$ \\ Robert B. Zajonc Institute of Social Science, Social Challenges Unit, University of Warsaw, Poland

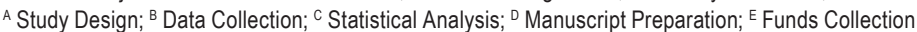 \\ Address for correspondence: \\ Paweł Zembura \\ Centrum Wyzwań Społecznych Uniwersytetu Warszawskiego \\ DELab UW \\ Dobra 56/66, 00-312 Warszawa, Poland \\ E-mail: pzembura@wp.pl
}

\begin{abstract}
Ahstract The aim of this study was to identify clusters based on four energy - balance related behaviours (EBRBs) - moderatevigorous physical activity, screen time, breakfast consumption and sweet drinks consumption - among adolescents participating in a governmental programme to increase their sport participation. The study was a part of the monitoring and evaluation process of a nationwide sport intervention in Poland. The sample consisted of 367 participants ( 180 females and 187 males, mean age $15.18 \pm 1.67$ ). Data was self-reported. Based on combination of cluster analysis, a five-cluster solution was found the most suitable. Some patterns of EBRBs were similar to the results obtained in previous studies conducted on the general population on, for example "sedentarysnacking" or "all-round-healthy" clusters. The amount of the clusters which accumulated most of the negative or positive behaviours were small, and most clusters presented a mix of behavioural patterns influencing energy balance in both positive and negative ways. The structure of the clusters differed based on adolescents' gender and, for male participants, fathers' education $(p<0.05)$.
\end{abstract}

Key Words cluster analysis, co-occurrence, sport intervention, MVPA, screen time

\section{Introduction}

Overweight and obesity are the effects of a positive energy balance over time (Hill, Wyatt, Peters, 2012). In Poland most children and adolescents fail to meet guidelines regarding behaviours that positively influence energy balance (Jodkowska, Oblacińska, Tabak, 2014; Mazur, 2015). For example, in a recent Health Behaviour in School-aged Children (HBSC) study only about $18 \%$ of 15 -years old teenagers reached the recommended 1 hour of moderate or vigorous physical activity (MVPA) daily and this level has not significantly changed during last 4 years (Mazur, 2015). Furthermore, the conclusion from the HBSC study is that meeting recommendations regarding physical activity (PA) and sedentary time is less common in older age groups of children (Mazur, 2015). 
Given these alarming patterns, since 2014 several nationwide sport interventions aiming to increase PA among schoolchildren have been introduced in Poland. The programmes, co-financed by Ministry of Sport and Tourism, are based on a simple model - afterschool, multisport classes organised 3 times a week and intended to reach children and adolescents previously not involved in organized sport. None of the programmes aimed to influence any other EBRBs, particularly sedentarism or eating habits. The emphasis has been strictly on MVPA.

From the public health perspective narrowing interventions, targeted to adolescents endangered by lack of PA, merely to sport could be viewed as a wasted opportunity, as they limit potential impact to just one behaviour. In multiple studies it has been shown, that among children and adolescents risks associated with modifiable health related behaviours coexist together within individuals (Fernández-Alvira et al., 2013; Leech, McNaughton, Timperio, 2014). Furthermore, they may carry synergetic influence on health outcomes (Busch, Van Stel, Schrijvers, de Leeuw, 2013; Gubbels, van Assema, Kremers, 2013). This has lead to extensive studying of clusters of children and adolescents who show similar behavioural patterns. One of the repeated conclusions included in the Leech et al. (2014) review was, that if the goal of the intervention is to prevent negative health outcomes, some behaviours might be targeted simultaneously.

In this study, our aim was to identify co-occurrence of EBRBs among adolescents involved in the intervention to increase physical activity. We were aware that behavioural patterns among adolescents involved in PA interventions might be very different from EBRBs coexistence in the general population. A better understanding of patterns, especially in comparison to population, should enable a data-driven re-shaping of the intervention (Gubbels et al., 2013). Moreover, information about clustering patterns for EBRBs is inconclusive (Leech et al., 2014). Cluster analysis is usually conducted to find populational patterns, and clusters are specific and not aimed to generalise (Leech et al., 2014). Finally, overall data about the coexistence of health-related behaviours in Poland among adolescents is scarce, apart from the work of Jodkowska et al. (2014), Mazur et al. (2014) and Zalewska et al. (2015).

For clustering, we chose four established EBRBs: level of MVPA; screen time spent watching TV and/ or playing computer or console games as representative of a sedentary lifestyle; and two factors representing dietary habits: soft drinks consumption and frequency of breakfast consumption. Previous studies and reviews showed evidence that PA, sedentary behaviour, breakfast consumption, and soft drink consumption are related to overweightness and obesity among children (Chinapaw, Proper, Brug, Van Mechelen, Singh, 2011; De Bourdeaudhuij et al., 2013; Massougbodji, Bodo, Fratu, Wals, 2014; Mitchell, Rodriguez, Schmitz, Audrain-McGovern, 2013; ReyLopez, Vicente-Rodríguez, Biosca, Moreno, 2008; Rezende, Rodrigues Lopes, Rey-López, Matsudo, Luiz, 2014; Szajewska Ruszczynski, 2010). A comprehensive review conducted as part of the ENERGY project acknowledged that the most evidence for an association with overweight and obesity in 10-12-year-old children was found for these four EBRBs (Douthwaite, Summerbell, Moore, 2012).

To obtain wider information about the clusters we compared them based on gender, age, parents' education and place of living. These factors were frequently investigated in previous studies, and several EBRBs consistently showed differences based on them (Brug et al., 2012; Gubbels et al., 2013; Leech et al., 2014; Ottevaere et al., 2011; Stierlin et al., 2015). For example, levels of physical activity tend to decrease with age as lower numbers of adolescents reach recommended MVPA when transitioning to adulthood (Mazur, 2015). 


\section{Objectives}

1. Identifying clusters based on EBRBs among adolescents participating in a PA intervention.

2. Comparing the obtained clusters based on socio-demographical variables.

\section{Methods}

\section{Study settings}

Data comes from the monitoring and evaluation stage of the intervention, in which one of the tools was an online questionnaire which participants were asked to complete. Parents or legal guardians provided written informed consent about their children's participation in the study. This nationwide intervention reaches about 35 thousand adolescents per annum. The goal of this programme is to organise systematic, free-of-charge, accessible training for adolescents from lower- and higher-middle schools. Each "Animator" (trainer) conducts three 90 minutes training sessions per week. Training sessions take place in sport clubs (which are frequently located on school grounds). Adolescents participating in the intervention were recruited primarily by physical education teachers, sport clubs, and trainers, so it was hypothesized that some of the participants might be already active.

For the purpose of the study subjective measurements were used, as all the behaviours were self-reported by adolescents through the online survey. Questionnaires were conducted during the first week of November, as recommended by IPAQ protocol (IPAQ Research Committee, 2005). Data collection was anonymous and the demographic information collected did not permit identification of the individual participant.

\section{Participants}

Data was gathered from 624 participants, however after omitting individuals with any missing values and extreme values the dataset was limited to 367 participants (59\%, 180 girls and 187 boys). The mean age in the sample was 15.18 years (SD 1.67).

\section{Measurements}

\section{Physical activity}

To assess physical activity, a short form of IPAQ (IPAQ Research Committee, 2005) was used. The original IPAQ is a self-administered questionnaire, which was primarily developed as a cross-national tool for monitoring PA and inactivity in adults and adolescents (15-69 years). In Poland, the short version of IPAQ is a frequently used measurement tool, even though its reliability and validity has not been extensively tested. The questionnaire enquires about activity during the previous week. The questions refer to four activity types of behaviour: "vigorous activity" periods for at least 10 min; "moderate activity" periods for at least 10 min, "walking" periods for at least 10 min and time spent "sitting" on weekdays. Frequency of activity is measured in days and duration in minutes. For the cluster analyses, the total time spent on moderate and vigorous activity was calculated and divided by 7 . The World Health Organization (WHO) recommends that children and adolescents aged 5-17 should undertake at least 60 minutes of moderate to vigorous intensity PA per day (Currie, 2012). For the purpose of descriptive statistics we examined how many participants reached a total of 7 days of vigorous and moderate physical activity per week 
and 60 minutes of vigorous and moderate activity per day. However, due to characteristics of IPAQ it is not possible to directly compare this result with the levels recommended by World Health Organization.

\section{Screen-based Sedentapy Behaviours (SB)}

The average time spent per day engaged in screen activities was calculated as a proxy for sedentary behaviour. Screen time was assessed separately for weekdays and weekend days. We used items from the HBSC questionnaire describing two types of screen time behaviour (Currie, 2012; Mazur, Małkowska-Szkutnik, 2011):

- watching television (including videos and DVDs),

- playing computer or console games (such as Playstation, Xbox).

Adolescents were asked to declare the amount of time spent, on average, on each activity in one day. Weighted mean duration of each behaviour per day ((5 weekday $\mathrm{min} / \mathrm{d}+2$ weekend $\mathrm{min} / \mathrm{d}) / 7$ ) was derived and calculated to provide the measure of screen time used in the cluster analysis.

For the purpose of descriptive statistics, the answers provided by adolescents for both questions were calculated and then categorized according to screen time recommendations for children and adolescents ( $>2 \mathrm{hr} /$ day; and $\leq 2 \mathrm{hr} /$ day) provided by the American Academy of Pediatrics. Sedentary behaviour for more than 2 hours per day has also been mentioned by Tremblay et al. (2011) as being associated with unfavourable body composition, decreased fitness, lowered scores for self-esteem and pro-social behaviour, and decreased academic achievement in school-aged children and youths.

\section{Frequency of eating hpeaklfast}

For breakfast consumption, we used HBSC items, previously translated to Polish (Currie, 2012; Mazur, Małkowska-Szkutnik, 2011). It comprised of two questions relating to weekdays and weekends: "How often do you usually have breakfast (more than a glass of milk or fruit juice)?" The response options for weekdays were "I never have breakfast during weekdays/one day" / "two days" / "three days" / "four days" / "five days" and for weekends "I never have breakfast during the weekend" / "I usually have breakfast on only one day of the weekend (Saturday or Sunday)" / "I usually have breakfast on both weekend days (Saturday and Sunday)". For cluster analysis, we used number of days of breakfast consumption. For the purpose of descriptive statistics, adolescents were considered regular breakfast eaters if they consumed breakfast 7 days a week.

\section{Consumption of sweet heverages}

For sugary drink consumption, another HBSC item was used (Mazur, Małkowska-Szkutnik, 2011). Participants answered the question "How many times a week do you consume sweetened soft drinks" with response options "never/less than once a week" / "two to four times a week" / "five to six times a week" / "once a day" / "more than once a day". For cluster analysis, we used representation of the scale from 1 ("never") to 6 ("more than once a day"). For the purpose of descriptive statistics children were divided into two groups - those who consumed sweet drinks less than twice per week ("1") versus those who consumed two or more times ("0" - was considered the unhealthy lifestyle behaviour group). 


\section{Socio-demographical variables}

Clusters were compared based on socio-demographical variables: gender, age, place of living, parents education level (mother's education level, father's education level). Categorical variables were created for this purpose. In reference to age, participants were divided to younger (12-14) and older (15-19) groups. For place of living, three classes were created: countryside, small towns (up to 20 thousand citizens), medium and large cities (above 20 thousand). For educational level, we created a binary variable where upper middle education was the highest level of lower class, and post-upper middle education was considered upper class.

\section{Statistical analysis}

First, we excluded outliers and truncated IPAQ data based on processing rules featured in the protocol, and excluded extreme values from the screen time variable (IPAQ Research Committee, 2005). Regarding moderate and vigorous physical activity we excluded maximal outliers (>960 total minutes per day including time spent walking) and truncated remaining high values of a particular type of activity to a maximum of 180 . For screen time, we excluded observations where screen time average exceeded 12 hours daily and truncated other high results of any type of screen time to 8 hours per day. Data was excluded from the analysis if time spent on all screen time activities (including another item describing time working on a computer) reached 16 hours or above or if a single activity reached or exceeded an average of 8 hours per day. For the purpose of descriptive statistics, meeting the cut-off criteria in the sample was compared based on gender using $X^{2}$.

As the factors were assessed on different scales, the variables included in the analysis were transformed to Z-scores (with mean = 0 and SD $=1$ ) to equalize their contribution in the cluster analysis (Hair, Black, 2000). Before clustering, we checked for multicollinearity and Pearson's correlations between variables.

A combination of hierarchical method and k-means cluster analysis was used to identify clusters for four EBRBs (Everitt, Landau, Leese, Stahl, 2011). First, we conducted hierarchical cluster analysis using the Ward method based on squared Euclidian distances. This step was used to identify and compare several possible cluster solutions based on the elbow method, dendogram solution and average silhouette width. In the second step, we used k-means cluster analysis to refine the solution from hierarchical clustering. A third step was the examination of stability (reliability of the final cluster solutions). This was done by randomly taking subsamples of the data (50 and $70 \%$ of observations from the dataset) separately conducting the two aforementioned clustering analyses and comparing the classification of the observations with the final cluster solution using kappa statistics.

To compare z-scores for EBRBs between the clusters, ANOVA and Games-Howell post hoc tests were used.

$X^{2}$ tests were used to examine gender distribution between the clusters. After clusters were stratified for gender, $X^{2}$ tests were performed to compare cluster distributions for age, place of living and parents' education.

Cluster analysis was carried out using R 3.2.3 with NbClust for analysing cluster solutions (Charrad, Ghazzali, Boiteau, Niknafs, Charrad, 2014). The remaining analyses were carried out using SPSS 21.

\section{Results}

Comparison of the proportion of participants meeting established cut-off levels of EBRB showed differences based on gender. A non-significant relationship was found only in the case of MVPA, while the larger proportion of 
females met cut-offs regarding screen time and sweet beverage consumption and the larger proportion of males regularly ate breakfast.

Tahle 1. Differences in meeting cut-off points of particular EBRB in the sample, based on gender

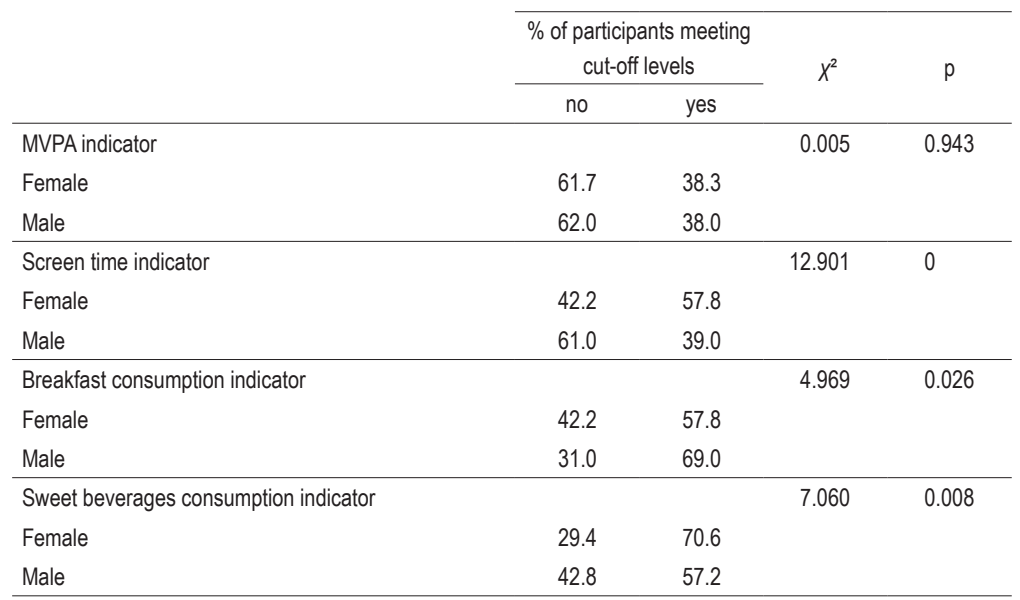

Cut-off points regarding EBRB:

MVPA - days of moderate activity + days of vigorous activity $\geq 7$ days per week and average time of moderate activity per day + average time of vigorous activity per day $\geq 60$ min. Screen time - watching TV + playing computer games or console $\leq 2 \mathrm{hr}$ per day.

Breakfast consumption - breakfast consumption 7 days a week.

Sweet beverages consumption - sweet beverages consumption less than two times per week.

Variance inflation factors were less than 1.5, suggesting that the shared variance between the clustering variables was sufficiently small that each variable could contribute to the cluster analysis (Hair, Black, 2000). The highest correlation between the EBRBs was 0.24 , and it described the relation between screen time and sweet beverage consumption. Other correlations were non-significant $(p<0.05)$.

Table 2. Inter-correlation between the EBRBs in the sample

\begin{tabular}{llccc}
\hline & MVPA & screen time & breakfast consumption & sweet beverages consumption \\
\hline MVPA & 1 & 0.003 & 0.050 & 0.015 \\
Screen time & 0.003 & 1 & -0.029 & 0.235 \\
Breakfast consumption & 0.050 & -0.029 & 1 & -0.025 \\
Sweet beverages consumption & 0.015 & 0.235 & -0.025 & 1 \\
\hline
\end{tabular}

To check the stability of the cluster analysis solution we randomly took subsamples from the dataset, conducted hierarchical and k-means clustering and compared the obtained results with cluster results for the whole sample. Cohen's Kappa к for $50 \%$ of the data was 0.75 which suggested substantial agreement, and for the subsample consisting of $70 \%$ of the data $\mathrm{K}=0.95$ which suggested almost perfect agreement (Viera, Garrett, 2005). 
Clustep solution

Based on the 4 behaviours (MVPA, screen time, breakfast consumption, sugar drinks consumption), a 5-cluster solution seemed the most adequate and reliable representation of this study population. ANOVA with Games-Howell post hoc comparisons were used to test for differences across the clusters.

The first cluster $(n=88$ ) was labelled Sweet Drinks Consumers for the higher results of sweet drinks consumption variable than in the other clusters. The second cluster $(n=45)$ was named Breakfast Skippers, as the z-scores for breakfast consumption were lower than in the other groups. This cluster also had a low z-score mean $(-0.45)$ for screen time. Third cluster $(n=156)$ was labelled Healthy Diet Low MVPA. It included the most observations and was not strongly distinct from the other clusters based on a single factor $(p<0.001)$. However, this cluster had higher z-scores for breakfast consumption than 2 clusters $(p<0.001)$. The fourth cluster $(n=40)$ was labelled Unhealthy Cluster, and was primarily distinguished by very high z-scores regarding screen time. This group agglomerated two other unhealthy behaviours, having breakfast consumption lower than 2 other clusters and sweet drinks consumption higher than 2 other clusters $(p<0.001)$. Finally, the fifth cluster $(n=38)$ was labelled High MVPA having higher $z$-scores for MVPA than other clusters $(p<0.001)$. This cluster also had a relatively high mean for breakfast consumption and low mean for screen time.

Tahle 3. Results of ANOVA with Games-Howell post-hoc comparisons between the clusters (z-scores)

\begin{tabular}{|c|c|c|c|c|c|c|c|}
\hline Cluster name & $\begin{array}{l}\text { Sweet drinks } \\
\text { consumers }\end{array}$ & $\begin{array}{l}\text { Breakfast } \\
\text { skippers }\end{array}$ & $\begin{array}{l}\text { Healthy diet } \\
\text { low MVPA }\end{array}$ & $\begin{array}{l}\text { Unhealthy } \\
\text { cluster }\end{array}$ & High MVPA & $\mathrm{F}$ (ANOVA) & $\begin{array}{c}\text { Post-hoc differences } \\
\text { between groups }\end{array}$ \\
\hline Cluster (N) & 88 & 45 & 156 & 40 & 38 & & \\
\hline MVPA & -0.2 & -0.31 & -0.34 & 0.21 & 2.15 & $107.71^{*}$ & $d, g, i, j$ \\
\hline$X \pm S D$ (min/day) & $56.87 \pm 37.17$ & $51.25 \pm 34.19$ & $49.72 \pm 30.49$ & $79.32 \pm 46.52$ & $183.16 \pm 49.61$ & & \\
\hline Screen time & -0.05 & -0.45 & -0.36 & 2.1 & -0.45 & $128.59^{*}$ & $c, f, h, j$ \\
\hline$X \pm S D(\min /$ day $)$ & $151.66 \pm 72.51$ & $104.6 \pm 70.96$ & $115.65 \pm 69.93$ & $399.75 \pm 87.98$ & $105.39 \pm 84.33$ & & \\
\hline Breakfast consumption & 0.34 & -1.99 & 0.47 & -0.31 & 0.22 & $179.87^{\star}$ & $a, e, f, g, h$ \\
\hline $\mathrm{X} \pm \mathrm{SD}$ (days/week) & $6.47 \pm 0.98$ & $2.02 \pm 1.14$ & $6.72 \pm 0.62$ & $5.23 \pm 1.91$ & $6.24 \pm 1.42$ & & \\
\hline Sweet drinks consumption & 1.05 & -0.29 & -0.65 & 0.32 & -0.41 & $86.69^{*}$ & $a, b, d, h$ \\
\hline$X \pm S D(1-7$ - ordered $)$ & $4.52 \pm 0.99$ & $2.73 \pm 1.07$ & $2.26 \pm 0.69$ & $3.55 \pm 1.34$ & $2.58 \pm 1.11$ & & \\
\hline
\end{tabular}

MVPA = Moderate to Vigorous Physical Activity .

${ }^{*} P<0.001$.

a - significant difference between 1st and 2nd cluster; $b$ - significant difference between 1st and 3rd cluster; $c$ - significant difference between 1 st and 4 th cluster; $d$ - significant difference between 1 st and 5 th cluster; $\mathrm{e}$ - significant difference between $2 \mathrm{nd}$ and $3 \mathrm{rd}$ cluster; $\mathrm{f}$ - significant difference between $2 \mathrm{nd}$ and 4 th cluster; $g$ - significant difference between 2 nd and 5 th cluster; $\mathrm{h}$ - significant difference between 3rd and 4th cluster; $\mathrm{i}$ - significant difference between $3 \mathrm{rd}$ and 5 th cluster; $\mathrm{j}$ - significant difference between 4th and 5 th cluster.

\section{Psychosocial Characteristics of Clusters}

In Table 4, the associations between the five clusters and the socio-demographic variables (gender, age category, place of living category, mother's education level and father's education level) are presented. For gender, significant differences could be found in the clusters' structures $\left(X^{2}=14.17, p=0.007\right)$. Post-hoc tests showed a higher presence of females in the Breakfast Skippers cluster in comparison to the Unhealthy Cluster and High MVPA cluster. For that reason analysis was carried out for each gender separately. Among males clusters' structures differed according to father's education level $\left(X^{2}=9.94, p<0.05\right)$. For females no significant relationships were 
observed $(p<0.05)$. However, we acknowledged an association between same sex parent education levels with the participant's presence in particular cluster. Higher proportions of lower educated parents tended to be observed among the Sweet Drink Consumers and Breakfast Skippers when compared to High MVPA and Unhealthy Cluster, although differences between particular clusters were not significant at $p<0.05$.

Table 4. Comparison of adolescents in the clusters based on socio-demographical variables

\begin{tabular}{|c|c|c|c|c|c|c|c|c|c|c|}
\hline \multicolumn{3}{|c|}{ Cluster } & $\begin{array}{l}\text { Sweet Drinks } \\
\text { Consumers }\end{array}$ & $\begin{array}{l}\text { Breakfast } \\
\text { Skippers }\end{array}$ & $\begin{array}{l}\text { Healthy Diet } \\
\text { Low MVPA }\end{array}$ & $\begin{array}{l}\text { Unhealthy } \\
\text { Cluster }\end{array}$ & High MVPA & Overall & \multirow{2}{*}{$x^{2}$} & \multirow[t]{2}{*}{$p$} \\
\hline & & & \multicolumn{6}{|c|}{$\%$} & & \\
\hline \multirow{2}{*}{ Gender } & female & 180 & 41 & 67 & 55 & 38 & 37 & 49 & 14.17 & 0.007 \\
\hline & male & 187 & 59 & 33 & 46 & 63 & 63 & 51 & & \\
\hline \multicolumn{11}{|l|}{ Female } \\
\hline \multirow{2}{*}{ Age group } & $12-14$ & 71 & 39 & 40 & 45 & 33 & 14 & 39 & 4.94 & 0.294 \\
\hline & $15-18$ & 109 & 61 & 60 & 55 & 67 & 86 & 61 & & \\
\hline \multirow{3}{*}{ Place of living } & village & 79 & 39 & 43 & 39 & 33 & 36 & 39 & 7 & 0.537 \\
\hline & small city & 36 & 25 & 10 & 25 & 13 & 7 & 20 & & \\
\hline & $\begin{array}{l}\text { average, } \\
\text { large city }\end{array}$ & 74 & 36 & 47 & 37 & 53 & 57 & 41 & & \\
\hline \multirow{2}{*}{$\begin{array}{l}\text { Education level } \\
\text { mother }\end{array}$} & lower & 94 & 53 & 70 & 49 & 53 & 29 & 52 & 7.22 & 0.125 \\
\hline & higher & 86 & 47 & 30 & 51 & 47 & 71 & 48 & & \\
\hline \multirow{2}{*}{$\begin{array}{l}\text { Education level } \\
\text { father }\end{array}$} & lower & 116 & 78 & 70 & 59 & 67 & 50 & 64 & 5.68 & 0.225 \\
\hline & higher & 64 & 22 & 30 & 41 & 33 & 50 & 36 & & \\
\hline \multicolumn{11}{|l|}{ Male } \\
\hline \multirow{2}{*}{ Age group } & $12-14$ & 68 & 46 & 40 & 37 & 24 & 25 & 36 & 5.23 & 0.264 \\
\hline & $15-18$ & 119 & 54 & 60 & 63 & 76 & 75 & 64 & & \\
\hline \multirow{3}{*}{ Place of living } & village & 64 & 37 & 60 & 34 & 20 & 29 & 34 & 14.06 & 0.08 \\
\hline & small city & 37 & 29 & 13 & 17 & 24 & 8 & 20 & & \\
\hline & $\begin{array}{l}\text { average, } \\
\text { large city }\end{array}$ & 86 & 35 & 27 & 49 & 56 & 63 & 46 & & \\
\hline \multirow{2}{*}{$\begin{array}{l}\text { Education level } \\
\text { mother }\end{array}$} & lower & 104 & 56 & 60 & 56 & 52 & 54 & 56 & 0.29 & 0.991 \\
\hline & higher & 83 & 44 & 40 & 44 & 48 & 46 & 44 & & \\
\hline \multirow{2}{*}{$\begin{array}{l}\text { Education level } \\
\text { father }\end{array}$} & lower & 112 & 67 & 80 & 62 & 40 & 46 & 60 & 9.94 & 0.042 \\
\hline & higher & 75 & 33 & 20 & 38 & 60 & 54 & 40 & & \\
\hline
\end{tabular}

\section{Discussion}

The main aim of the study was to examine clustering of EBRBs among Polish adolescents involved in a largescale public intervention aimed at increasing physical activity. Based on the comparable indicators, the studied group showed favourable EBRBs over the populational sample in the similar age group (higher frequency of breakfast consumption, lower consumption of sweet beverages) (Mazur, 2015). The cluster solution indicated that merely healthy or unhealthy behaviours seldom coexist together within individuals, yet some established mixed patterns of EBRBs were found.

A mix of healthy and unhealthy behaviours was noted in four clusters, and in one cluster (High MVPA) only healthy behaviours were present. This structure of the groups is coherent with a more general trend, where the 
largest clusters represent a mix of healthy and unhealthy behavioural patterns, while a minor number of clusters, constituting small part of a sample, accumulates either healthy or unhealthy behaviours (Jodkowska et al., 2014; Leech et al., 2014).

\section{Cluster solution}

The most noticeable clusters in our study were Healthy Diet Low MVPA, Unhealthy Cluster and High MVPA. Healthy Diet Low MVPA was the largest cluster (43\%), without a single extreme value regarding one factor, but defined by relatively healthy dietary patterns with low MVPA and screen time. The size of this cluster seems prominent given the group under study - adolescents taking part in the organized PA at least 5 times a week ( 3 from intervention, 2 from obligatory PE class at school). Clusters with a similar structure were substantial in studies conducted in the other countries (lannotti, Wang, 2013; Ottevaere et al., 2011; Seghers, Rutten, 2010).

High MVPA cluster accumulated all healthy behaviours. The Unhealthy Cluster included negative scores for three out of the four health indices. However, the Unhealthy Cluster, with remarkably high levels of screen time, was not characterised by a low level of MVPA, which reflects the previous conclusion that sedentary time does not have to displace PA (Pearson, Braithwaite, Biddle, van Sluijs, Atkin, 2014). The lack of consistency regarding relationships between MVPA and sedentary time is continuously found in cluster analysis (Leech et al., 2014). While some have suggested that those who engage in less PA are more likely to watch a lot of TV, in most studies just a weak relationship, if any, is found between MVPA and screen-based sedentary activities. Clusters are instead primarily determined by just one of these variables (Pearson et al., 2014; Pérez-Rodrigo et al., 2015). Furthermore, as mentioned by Ottevaere et al. (2011) people might consciously or unconsciously compensate for unhealthy behaviours (screen time, dietary patterns) with leptogenic behaviours, which may explain relatively high levels of MVPA in the Unhealthy Cluster.

Some similarities with previously obtained cluster solutions were found in our study. The High MVPA cluster concurred with the popular "all-round-healthy" pattern mentioned by Gubbels et al. (2013), where high levels of physical activity is combined with a healthier diet and low levels of sedentary behaviour (Cuenca-García et al., 2013; Gubbels et al., 2013; lannotti, Wang, 2013; Pérez-Rodrigo et al., 2015). Another universal pattern was found in the study: in the Unhealthy Cluster we identified a "sedentary-snacking" sub-cluster mixing screen time with unhealthy nutrition, which has previous been acknowledged in multiple studies (Gubbels et al., 2013; lannotti, Wang, 2013). Its structure was also similar to the Unhealthy Diet \& Active cluster from the study of Cuenca-García et al. (2013) and "High Activity/High Sedentary" cluster found by Jago et al. (2010).

\section{Socio-demographical variables}

In order to identify high-risk groups that could be targeted by preventive interventions, it is important to be able to predict which adolescents are likely to show particular behavioural patterns. Children and adolescents' gender has been consistently associated with their pattern scores. In this study, we found differences in meeting cut-off values for particular EBRBs based on gender, as well as the association between gender and cluster patterns. Interestingly, we did not find a relationship between gender and meeting established levels for MVPA, which was the case in the study conducted by Jodkowska et al. (2014) and is one of the most steady trends in Polish studies (Mazur, 2015). Other associations between EBRBs and gender were coherent with observations from several studies. The trend of a lower percentage of breakfast skippers among males was consistent with a previous study in 
Poland (Jodkowska et al., 2014). On the other hand, girls were less likely to drink sweet beverages, what was noted by Dzielska (2012). Boys also reported more time spent on screen time behaviours, which is a general pattern, as concluded by Bucksch et al. (2016).

One of the more conclusive findings from the review conducted by Leech et al. (2014) was that clusters with lower PA were comprised of older participants, especially females. In our study, the Unhealthy Cluster consisted mainly of older adolescent males, and the High MVPA cluster had very similar gender and age proportions. As we found four clusters to be grounded foremost on the extreme values of a particular EBRB, their structures reflect a factor's association with gender. For example, Breakfast Skippers consisted primarily of females (67\%) as this unhealthy pattern was more frequently observed among females in the sample.

Higher proportions of lower educated parents were observed in the clusters with particularly strong single unhealthy dietary habits. This was also the case in other studies, where low quality of diet and levels of PA were associated with lower education of the parents (Fernández-Alvira et al., 2013; Leech et al., 2014). However, this does not imply that there is a reverse linkage between higher education of parents and healthy clusters, since a high education level of parents was noted in both the High MVPA and Unhealthy Cluster, which was not the case in most other studies. Such a contradictory relationship may be explained by the general trend in sedentary time, which reported a positive association of sedentary behaviour with lower socioeconomic status background, as well as living in a household with more access to televisions/computers (Pate, Mitchell, Byun, Dowda, 2011).

\section{Pragmatic summary}

From a project management standpoint, cluster analysis provided valuable information about the participants. First, it is crucial to understand the prevalence of unhealthy EBRB in the studied group and the weak, if any, relationship between the levels of MVPA and other EBRB. Second, we found different socio-demographical structures of the clusters, suggesting other risks factors regarding particular EBRBs based on participants' gender and their unclear association with parental education. For girls we noticed a high prevalence of breakfast skipping, while boys recorded a higher amount of screen time and sweet drink consumption. A more general observation is that fraction of girls exceeded boys in the clusters characterised by little energy consumption and little energy expenditure ("not consuming - not moving" pattern). On the other hand, there were much more boys in the clusters with high MVPA and high sweet drink consumption, hence boys fit the "consuming - moving" pattern more often.

Furthermore, it seems essential to acknowledge the structure of cluster in which negative behaviours, except for the levels of MVPA, accumulated. In the group of participants who were in general physically active, we found the same universal "sedentary-snacking" pattern, which has been noted in a few studies in European contexts (Gubbels et al., 2013). This sedentary cluster is formed foremost of males. It is also worth noting that although girls are targeted as a risk group in terms of lowest levels of PA, general health outcomes (obesity prevalence) is significantly higher among boys (according to Mazur (2015)): $18 \%$ of 15 -years old boys and only $6 \%$ girls deal with overweightness and obesity in Poland). If the intervention strategy progresses towards greater interest in healthy lifestyle rather than just increasing MVPA, this group should become a natural target of interest, given that sedentarism is considered a strong predictor of health-risks (Rezende et al., 2014). To sum up, describing adolescents participating in the intervention just as "sporty kids" would be a dangerous oversimplification, given the existence of behavioural patterns similar to those obtained in populational studies. 


\section{Conclusions}

1. Co-occurrence of EBRBs in the studied group is complicated as EBRBs do not necessary cluster together in a negative or positive ways.

2. Based on four EBRBs, a five cluster solution was found the most compelling. Cluster structures were primarily determined by high results of one variable.

3. The size of the clusters which accumulated most of the negative or positive behaviours, was small.

4. Some patterns of EBRB in adolescents involved in the PA intervention were similar to the results obtained in previous studies conducted on the general population, for example "sedentary-snacking" or "all-round-healthy" clusters.

5. Cluster structures differed based on adolescents' gender and fathers' education level for male participants.

\section{References}

Brug, J., Van Stralen, M., te Velde, S., Chinapaw, M., De Bourdeaudhuij, I., Lien, N., Bere, E., Maskini, V., Singh, A., Maes, L., Moreno, L., Jan, N., Kovacs, E., Lobstein, T., Manios, Y. (2012). Differences in Weight Status and Energy-Balance Related Behaviors among Schoolchildren across Europe: The ENERGY-Project. PLOS ONE, 7 (4), e34742.

Bucksch, J., Sigmundova, D., Hamrik, Z., Troped, P., Melkevik, O., Ahluwalia, N., Borraccino, A., Tynjälä, J., Kalman, M., Inchley, J. (2016). International Trends in Adolescent Screen-Time Behaviors from 2002 to 2010. Journal of Adolescent Health.

Busch, V., Van Stel, HF., Schrijvers, A.J., de Leeuw, J.R. (2013). Clustering of health-related behaviors, health outcomes and demographics in Dutch adolescents: a cross-sectional study. BMC Public Health, 13 (1), 1-19.

Charrad, M., Ghazzali, N., Boiteau, V., Niknafs, A., Charrad, M. (2014). Package 'NbClust'. J. Stat. Soft, 61, 1-36.

Chinapaw, M.J., Proper, K.I., Brug, J., Van Mechelen, W., Singh, A.S. (2011). Relationship between young peoples' sedentary behaviour and biomedical health indicators: a systematic review of prospective studies. Obesity Reviews, 12 (7), 621-632.

Cuenca-García, M., Huybrechts, I., Ruiz, J.R., Ortega, F.B., Ottevaere, C., González-Gross, M., Moreno, L.A., Vicente-Rodríguez, G., Molnár, D., Polito, A., Manios, Y., Plada M., Vanhelst, J., Widhalm, K., Sjöström, M., Kersting, M., Castillo, M.J., HELENA study group. (2013). Clustering of Multiple Lifestyle Behaviors and Health-Related Fitness in European Adolescents. Journal of Nutrition Education and Behavior, 45 (6), 549-557.

Currie, C., (2012). Social determinants of health and well-being among young people. Health Behaviour in School-aged Children (HBSC) study: international report from the 2009/2010 survey. Copenhagen: World Health Organization Regional Office for Europe.

De Bourdeaudhuij. I., Verloigne, M., Maes, L., Van Lippevelde, W., Chinapaw, M., Te Velde, S.J., ..., Brug., J. (2013). Associations of physical activity and sedentary time with weight and weight status among 10-to 12-year-old boys and girls in Europe: a cluster analysis within the ENERGY project. Pediatric Obesity, 8 (5), 367-375.

Douthwaite, W., Summerbell, C., Moore, H. (2012). Identifying the most important energy balance behaviours among 10-12 year olds, and their parents, that are associated with excessive weight gain and overweight. Retrieved from http://www.worldobesity.org/ site_media/uploads/wp2_-_phase_1_report.pdf.

Dzielska, A. (2012). Zachowania żywieniowe. In: B. Woynarowska, J. Mazur (eds.), Tendencje zmian zachowań zdrowotnych i wybranych wskaźników zdrowia młodzieży szkolnej w latach 1990-2010 (pp. 53-59). Warszawa: Instytut Matki i Dziecka.

Everitt, B.S., Landau, S., Leese, M., Stahl, D. (2011). Cluster Analysis (5th ed.). West Sussex: John Wiley \& Sons, Ltd.

Fernández-Alvira, J.M., De Bourdeaudhuij, I., Singh, A.S., Vik, F.N., Manios, Y., Kovacs, E., Moreno, L.A. (2013). Clustering of energy balance-related behaviors and parental education in European children: the ENERGY-project. Int J Behav Nutr Phys Act, 10, 5.

Gubbels, J., Van Assema, P., Kremers, S. (2013). Physical activity, sedentary behavior and dietary patterns among children. Current Nutrition Reports, 2 (2), 105-112.

Hair, J.F., Black, W.C. (2000). Cluster analysis. In Grimm L.G., Yarnold, P. R. Reading and understanding more multivariate statistics. Washington: American Psychological Association.

Hill, J.O., Wyatt, H.R., Peters, J.C. (2012). Energy balance and obesity. Circulation, 126 (1), 126-132.

lannotti, R., Wang, J. (2013). Trends in physical activity, sedentary behavior, diet, and BMI among US adolescents, 2001-2009. Pediatrics, 132 (4), 606-614. 
IPAQ Research Committee. (2005). Guidelines for data processing and analysis of the International Physical Activity Questionnaire (IPAQ) - short and long forms. Retrieved September, 17, 2008.

Jago R., Fox, K., Page, A., Brockman, R., Thompson, J. (2010). Physical activity and sedentary behaviour typologies of 10-11 year olds. Int J Behav Nutr Phys Act, 7, 59.

Jodkowska, M., Oblacińska, A., Tabak, I. (2014). How well do Polish teenagers meet health behaviour guidelines? Przegląd Epidemiologiczny, 68 (1), 65-70.

Leech, R., McNaughton, S., Timperio, A. (2014). The clustering of diet, physical activity and sedentary behavior in children and adolescents: a review. Int J Behav Nutr Phys Act, 11, 4.

Massougbodji, J., Bodo, Y., Fratu, R., Wals, P. (2014). Reviews examining sugar-sweetened beverages and body weight: correlates of their quality and conclusions. The American Journal of Clinical Nutrition, 99 (5), 1096-1104.

Mazur, J. (2015). Zdrowie i zachowania zdrowotne młodzieży w Polsce na tle wybranych uwarunkowań socjodemograficznych. Wyniki badań HBSC 2014. Warszawa: Instytut Matki i Dziecka.

Mazur, J., Kowalewska A., Baska, T., Sigmund, E., Nałęcz, H., Nemeth, A., Zawadzka, D. (2014). Patterns of Physical Activity and Multiple Risk Behaviour in Adolescents from Visegrad Countries. Zeszyty Naukowe Ochrony Zdrowia. Zdrowie Publiczne i Zarzadzanie, 12 (1), 56-67.

Mazur, J., Małkowska-Szkutnik, A. (2011). Wyniki badań HBSC 2010: raport techniczny. Warszawa: Instytut Matki i Dziecka.

Mitchell, J.A., Rodriguez, D., Schmitz, K.H., Audrain-McGovern, J. (2013). Greater screen time is associated with adolescent obesity: A longitudinal study of the BMI distribution from Ages 14 to 18. Obesity, 21 (3), 572-575.

Ottevaere, C., Huybrechts, I., Benser, J., De Bourdeaudhuij, I., Cuenca-Garcia, M., Dallongeville, J., ..., HELENA Study Group. (2011). Clustering patterns of physical activity, sedentary and dietary behavior among European adolescents: The HELENA study. BMC Public Health, 11, 328.

Pate, R.R., Mitchell, J.A., Byun, W., Dowda, M. (2011). Sedentary behaviour in youth. British Journal of Sports Medicine, 45 (11), 906-913.

Pearson, N., Braithwaite, R.E., Biddle, S.J.H., van Sluijs, E.M.F., Atkin, A.J. (2014). Associations between sedentary behaviour and physical activity in children and adolescents: a meta-analysis: Active and sedentary behaviours in youth. Obesity Reviews, $15(8), 666-675$.

Pérez-Rodrigo, C., Gil, Á., González-Gross, M., Ortega, R. M., Serra-Majem, L., Varela-Moreiras, G., Aranceta-Bartrina, J. (2015). Clustering of Dietary Patterns, Lifestyles, and Overweight among Spanish Children and Adolescents in the ANIBES Study. Nutrients, 8 (1).

Rey-Lopez, J.P., Vicente-Rodríguez, G., Biosca, M., Moreno, L.A. (2008). Sedentary behaviour and obesity development in children and adolescents. Nutrition, Metabolism and Cardiovascular Diseases, 18 (3), 242-251.

Rezende, L.F.M. de, Rodrigues Lopes, M., Rey-López, J.P., Matsudo, V.K.R., Luiz, O. do C. (2014). Sedentary Behavior and Health Outcomes: An Overview of Systematic Reviews. PLOS ONE, 9 (8), e105620.

Seghers, J., Rutten, C. (2010). Clustering of multiple lifestyle behaviours and its relationship with weight status and cardiorespiratory fitness in a sample of Flemish 11-to 12-year-olds. Public Health Nutrition, 13 (11), 1838-1846.

Stierlin, A.S., Lepeleere, S.D., Cardon, G., Dargent-Molina, P., Hoffmann, B., Murphy, M.H., ..., DEDIPAC Consortium. (2015). A systematic review of determinants of sedentary behaviour in youth: a DEDIPAC-study. Int J Behav Nutr Phys Act, 12 (1), 1-19.

Szajewska, H., Ruszczynski, M. (2010). Systematic review demonstrating that breakfast consumption influences body weight outcomes in children and adolescents in Europe. Critical Reviews in Food Science and Nutrition, 50 (2), 113-119.

Tremblay, M.S., LeBlanc, A.G., Kho, M.E., Saunders, T.J., Larouche, R., Colley, R.C., Goldfield, G., Gorber, S.C. (2011). Systematic review of sedentary behaviour and health indicators in school-aged children and youth. Int J Behav Nutr Phys Act, $8,98$.

Viera, A.J., Garrett, J.M. (2005). Understanding interobserver agreement: the kappa statistic. Fam Med, 37 (5), 360-363.

Zalewska, M., Genowska, A., Jamiołkowski, J., Nowak, R., Szpak, A., Maciorkowska, E. (2015). The Use of Cluster Analysis for NonContinuous Variables in the Assessment of Dietary Behaviours and Physical Activities in Primary School Children. Studies in Logic, Grammar and Rhetoric, 43 (1), 121-136.

Cite this apticle aS: Zembura, P., Gołdys, A. (2016). Co-Existence of Physical Activity (PA) and other Energy-Balance Related Behaviours among Adolescents Participating in PA Intervention in Poland. Central European Journal of Sport Sciences and Medicine, 16 (4), 43-54. DOI: 10.18276/cej.2016.4-05. 